\title{
7. The Fog Medium: Visualizing and Engineering the Atmosphere ${ }^{1}$
}

\author{
Yuriko Furuhata
}

\begin{abstract}
Yuriko Furuhata explores the fog sculptures of artist Nakaya Fujiko. Nakaya's deployment of fog and smoke recalls other expanded cinema practitioners and environmental artists in the postwar period, yet her experiments take on a different significance when seen not as a descendant of the phantasmagoria but as part of an assemblage linked to the development of smoke screens for aerial warfare. Paying particular attention to the dual function of fog screens - which obfuscate visibility yet also make visible such qualities as temperature, humidity, and wind-Furuhata historicizes the epistemological and political conditions behind the turn to fog and smoke within expanded cinema and the environmental arts during the Cold War. In so doing, Furuhata provides a geopolitically nuanced twist to the recent interest in 'atmospheric media' and 'elemental media'.
\end{abstract}

Keywords: Cold War, Pepsi Pavilion, Atmosphere, Peter Sloterdijk, Expanded Cinema

\section{Introduction}

Fogs, as Japanese artist Nakaya Fujiko once noted, are clouds that descend on earth. ${ }^{2}$ Recently, clouds have become a much-debated and researched topic in film and media studies. Terms such as 'atmospheric media' and

1 I want to thank Nakaya Fujiko, the Nakaya Ukichirō Foundation, and Julie Klüver Martin for their kind permission to reproduce images related to Nakaya Ukichirō's scientific research and the Pepsi Pavilion in this article. All the Japanese names follow the customary order of the family name first. All translations from Japanese sources are mine.

2 Nakaya, 1970, p. 106.

Buckley, C., R. Campe, F. Casetti (eds.), Screen Genealogies. From Optical Device to Environmental Medium. Amsterdam: Amsterdam University Press, 2019

DOI 10.5117/9789463729000_CHO7 
'elemental media' have gained popularity, alongside the metaphor of the cloud in cloud computing. Scholars as diverse as Weihong Bao, Mark Hansen, Tung-Hui Hu, John Durham Peters, Nicole Starosielski, and Antonio Somaini have prompted us to look at the affinity between media and atmospheric environment in a new light. ${ }^{3}$ To put it schematically, the old framework of media ecology represented by the Toronto School of communication studies à la Marshall McLuhan that regarded media as environments has given way to a more materialist, infrastructural, and genealogical study of technical media that become environmental. Conversely, scholars are now paying renewed attention to the mediating function of environmental elements such as air, water, and light as communicative and expressive media.

This chapter joins this growing field of atmospheric and elemental media studies by providing a genealogy of artificial fog as medium. More specifically, I turn to the dual functions of fog as both a screening device (which visualizes or obfuscates the environment) and as an atmospheric phenomenon in its own right. A focal point of this genealogical investigation is Nakaya Fujiko's 'fog sculptures'. First presented as an integral component of the Pepsi Pavilion at Expo '70, an event designed by the artist and engineer collective Experiments in Art and Technology (E.A.T.) to which Nakaya belonged, this exquisite artwork stands out as both a pioneering work of Japanese environmental art (kankyō geijutsu) and a salient example of what might be called an atmospheric screen. Consisting of water-based artificial fog, softly concealing the outer shell of the dome-shaped pavilion, this delicate work pushes our understanding of the screen beyond the assumed planarity of the projection surface. Unlike the common understanding of screen as a passive surface onto which images are projected, the atmospheric screen of the fog sculpture foregrounds its paradoxical capacity to conceal. And by concealing, it makes explicit the atmospheric phenomena that may otherwise go unnoticed. In other words, the making-visible of the atmosphere by the fog both parallels and goes beyond the making-visible of the image by the screen.

In what follows, I argue that an environmental artwork like Nakaya's fog sculpture not only participates in what Peter Sloterdijk has called the process of 'atmospheric-explication'- a process that transforms the taken-for-granted givenness of the environment into an explicit object of manipulation-but also links the history of art to the history of science and technology. ${ }^{4}$ Read through this framework of atmospheric-explication, the fog sculpture appears as more than a mere device for visual obfuscation 
and serves as a means of calling attention to larger historical processes of studying and controlling atmospheric phenomena. An exploration of this work also allows me to trace the genealogical background of artificial fog and its entanglement with warfare, cloud-seeding, and geoengineering. ${ }^{5}$

My argument is that the work of fog sculpture serves as a unique point of convergence between two heterogeneous lines of descent: on the one hand, the practice of visualizing atmospheric phenomena such as air currents, in which fog serves as projection and camouflage screen; and on the other, the practice of engineering the atmosphere, including weather control that artificially produces fog, rain, and snow. To trace a genealogy of the fog medium is to investigate how and why these lines of descent intersected at a specific moment through an interdisciplinary group of artists, scientists, and engineers coming from Japan and the United States, whose political alliance cemented during the Cold War. Seen from this geopolitical perspective, the historical timing of the fog sculpture matters a great deal. That is, the emergence of artificial fog as an artistic medium is inseparable from the larger geopolitical conditions of modernity in which the atmosphere was articulated with and as technical media.

\section{Visualizing the atmosphere}

Before turning to the fog sculpture at the Pepsi Pavilion, I want to briefly summarize the ways in which fog (and cloud-like substances in general) has long functioned as a screening and visualizing device. With the invention of electric light, clouds in the night sky became a medium of telecommunication. The nineteenth century witnessed an increased desire to reach the sky and turn clouds into a surface for projection. The clouds became a medium of 'celestial projection', a surface for projections that ranged from flashing Morse code for military communication to illuminated letters and pictures for commercial advertisements. In one such experiment with 'cloud telegraphy', a large mirror was used to bounce electric light as projected signals onto clouds. Some inventors such as Amos Dolbear even imagined that weather forecasts could one day be 'given by a series of flashes' reflected onto clouds. ${ }^{6}$ The idea of using clouds as a screen was also behind the 1893

5 An affinity between the fog sculpture and media is present in Peters's passing comment; artworks like fog and mist installations befittingly belong to 'an age of poison gas, cloud seeding, and geoengineering'. Peters, p. 255 .

6 Quoted in Marvin, p. 184. 
Chicago World's Fair's 'electric cloud projector' used to 'project the daily number of visitors in the daytime, and to beam texts and pictures in the clouds after dark'?

The idea of projecting images onto clouds, however, was not limited to marketing and military strategists. Magicians, artists, and scientists also saw the potential in combining electric light projections and gaseous screens. In the early nineteenth century, Belgian physicist and magician Étienne-Gaspard Robertson made use of smoke to enhance ghostly spectacles of his phantasmagoria. ${ }^{8}$ A similar desire to use the visual effect of smoke, fog, and cloud pervaded visual artists in the twentieth century. One salient example is László Moholy-Nagy's whimsical proposal to use 'clouds or artificial fog banks' for light projection work. ${ }^{9}$ His dream came true with the artistic use of dry ice and fog machines in theatrical performance, projection-based light art, and expanded cinema that flourished from the 196os onward. The most well-known work in this context is Anthony McCall's 'solid light film', Line Describing a Cone (1973), a work that combines the sculpting force of the light beam emitted by a film projector with the ambient effect produced by a smoke machine (or, in its early exhibition, cigarette smoke). ${ }^{10}$

A number of other artists and filmmakers have made similar attempts to incorporate cigarette smoke, dry ice fumes, and other gaseous substances as projection surfaces in their filmic and installation works. Japanese experimental filmmaker Matsumoto Toshio, for instance, initially planned to use smoke grenades and dry ice to create a three-dimensional ambient screen for his expanded cinema piece, Projection for Icon, at the international event Cross Talk/Intermedia in Tokyo in February 1969. Matsumoto ended up using helium-filled giant balloons as the projection surface, but his proposal speaks to the contemporaneous interest by experimental filmmakers who saw cloud-like substances as a potential technical support for expanded cinema. ${ }^{11}$ At Cross Talk/Intermedia, these same buoyant balloons were also used by the experimental filmmaker Iimura Takahiko and composer David Rosenbaum.

Cross Talk/Intermedia was conceptualized in the wake of 9 Evenings: Theater and Engineering (1966), a landmark intermedia event in New York.

7 Huhtamo, p. 335 .

8 Williamson, p. 107.

9 Casetti, p. 93.

10 MacDonald, p. 164.

11 Matsumoto Toshio writes: 'I had a desire to project onto something that was not [regular] screen [...] First, I imagined this work as a projection onto a gaseous body.' Matsumoto, n.p. 
Initiated by artist Robert Rauschenberg and Bell Laboratories engineer Billy Klüver, the occasion emblematized the art-and-technology movement of the era. Similarly, Cross Talk/Intermedia - the largest event in a series sharing its name - was intended to bring artists and engineers together, but this time with an explicit emphasis on facilitating collaborations among Japanese and American composers, musicians, and filmmakers. Experimental composers and musicians Roger Reynolds, Karen Reynolds, Akiyama Kuniharu, and Yuasa Jojji were the main organizers, and they invited filmmakers such as Matsumoto, Iimura, and Stan VanDerBeek as well as musicians such as Gordon Mumma, Robert Ashley, and Salvatore Martirano on board. Incidentally, Pepsi was one of the official sponsors, along with the United States Information Agency, which saw an opportunity to fold the event into its Cold War cultural diplomacy efforts that increasingly targeted left-leaning youths who vehemently opposed the Cold War military-industrial alliance between Japan and the United States. ${ }^{12}$

The artistic use of helium gas and inflatable, pneumatic objects also became popular during the 1950 s and 1960 . From Gutai group artist Kanayama Akira's Balloon (1956) to Robert Whitman's The American Moon (1960) and Andy Warhol's Silver Clouds (1966), artists frequently made use of plastic, a synthetic material whose availability increased in the postwar years, and helium-filled objects for their installation and film projection works. ${ }^{13}$ Similarly, visual artist Azuchi Shūzō Gulliver used a gigantic cylinder-shaped inflatable for his expanded cinema piece, Flying Focus (1969). Reminiscent of the early practice of celestial projection, images emitted from a slide projector were projected onto an upright cylinder floating against the night sky. ${ }^{14}$ This turn towards ephemeral screens made of vaporous particles in the air was also evident in a more commercially oriented attraction at Expo '70. The Japanese Tobacco Company's Rainbow Pavilion featured a 'smoke show' that combined spectacular light and film projections with a gigantic smoke screen generated by dry ice. This smoke screen belongs to the same lineage as Robertson, Moholy-Nagy, and Matsumoto's proposals to use vaporous particles hanging in the air as projection surfaces.

Yet light and film projections are only one part of the lineage of visualizing the atmosphere. Fog and smoke have also served as scientific instruments inside the laboratory. Given that the industrial pollution 
known as 'smog' - a combination of smoke and fog - is associated with aerial invisibility, the use of fog and smoke for visualizing atmospheric phenomena may seem counterintuitive. However, observing and analyzing natural atmospheric phenomena, including the formations of clouds and fog, often required their mimetic replication inside the enclosed space of the laboratory.

At the beginning of the twentieth century, French physicist Étienne-Jules Marey made use of chronophotography and smoke as instruments for visualizing and observing otherwise invisible atmospheric phenomenon of air currents, turning the malleable and opaque substance of smoke into a means of visualization. He built glass wind tunnels attached to a 'smoke machine' that spouted smoke streaks from a row of parallel nozzles. He would then place tiny objects in these wind tunnels to disturb the flow of air-and thus to alter the visible path of the smoke streaks. Marey documented the patterns created by these smoke trails in a series of stunning chronophotographs. Smoke here functioned as a sculptural medium for visualizing airflow, and photography worked as a graphic medium for recording this movement. ${ }^{15}$

Marey was by no means the first scientist to notice smoke's potential as a tool for the visualization and observation of airflow. French aeronautical engineer Alphonse Pénaud also observed how 'dust particles lit up by the sun would give a graphic picture of the disturbance of the air around birds'. In order to replicate this natural optical condition, Pénaud used jets of smoke to further study air turbulence, an experiment that anticipated the use of dust, smoke, and chemical fog by expanded cinema and light art practitioners in the mid-twentieth century. ${ }^{16}$

Such scientific deployment of cloud-like substances is an essential part of the history of the laboratory. Take, for instance, the invention of the cloud chamber by Scottish physicist and meteorologist Charles Thomson Rees Wilson. The cloud chamber is a scientific instrument used by atomic, nuclear, and particle physicists to visualize otherwise invisible atmospheric phenomena such as the passages of charged particles. Wilson's original

15 Hinterwaldner, p. 9. While Marey's proto-cinematic invention of chronophotography and his attention to the indexical trace of time occupies an important place in film and media studies, what draws my attention to his experiments is not the photographic record per se but his use of the smoke machine to visualize airflow. On Marey's experiments with the indexical trace of time, see Doane, 2002.

16 Braun, p. 217. Some critics have compared Nakaya Fujiko's fog sculpture to Marey's smoke photographs. Anne-Marie Duguet, for instance, notes that although Nakaya's primary objective is aesthetic, her creative process relies on rigorous scientific protocols of observation and experimentation. Duguet, p. 35 
impetus for building a sealed container with super saturated water vapour was to reproduce the cloud formations he observed as a meteorologist. The cloud chamber, in other words, was first designed to create artificial clouds in a controlled environment. To use Peter Galison's term, the cloud chamber was an instrument of 'mimetic experimentation', a term he uses to describe a series of scientific 'attempt[s] to reproduce natural physical phenomena, with all their complexity, in the laboratory'. ${ }^{17}$

It was these mimetic experiments-the reproduction and analysis of atmospheric phenomena such as rain, clouds, fog, lightning, and snow inside the simulated environment of the laboratory-that informed the later invention of the water-based artificial fog used by Nakaya Fujiko and her collaborators for the Pepsi Pavilion. To fully understand the genealogical significance of this fog sculpture therefore requires that we pay attention to the technological and scientific conditions that enabled the artist to turn artificial fog into an artistic medium. Just as the material history of microphysics cannot be narrated without the understanding of technical and epistemological impacts of instruments and machines that assisted scientists in their attempts to visualize, document, measure, and compute their experiments, unpacking the invention of the fog medium in a genealogical fashion demands that we understand the technological apparatus that supported this artwork: the fog-making machine. Furthermore, just as the construction of scientific instruments for experiments is bound up with their institutional as well as theoretical contexts, the fog-making machine used for the Pepsi Pavilion has its own historicity.

In order to understand the historicity of this apparatus, however, we must not simply look at the instrument itself but also broaden our scope to trace another genealogical connection: a familial connection between the artist and her father, Nakaya Ukichirō, a famed physicist who invented artificial snowflakes in the mid-1930s. (Figure 7.1) While critical and historical writings on Nakaya Fujiko's fog sculpture have made customary reference to this father-daughter relationship, they hardly go beyond anecdotal interpretations of their shared interests in meteorological phenomena. ${ }^{18}$ As we will see below, however, the connection between their work goes beyond their bloodline; it is the practice of engineering the atmosphere that binds the artist and the scientist.

18 Art critic Okazaki Kenjirō suggests that Nakaya Fujiko's keen interest in the observation of the structure and metamorphic process of fog formation comes from her father Ukichirō's devotion to the scientific analysis of the principles of snow crystallization. Okazaki, p. 69 . 


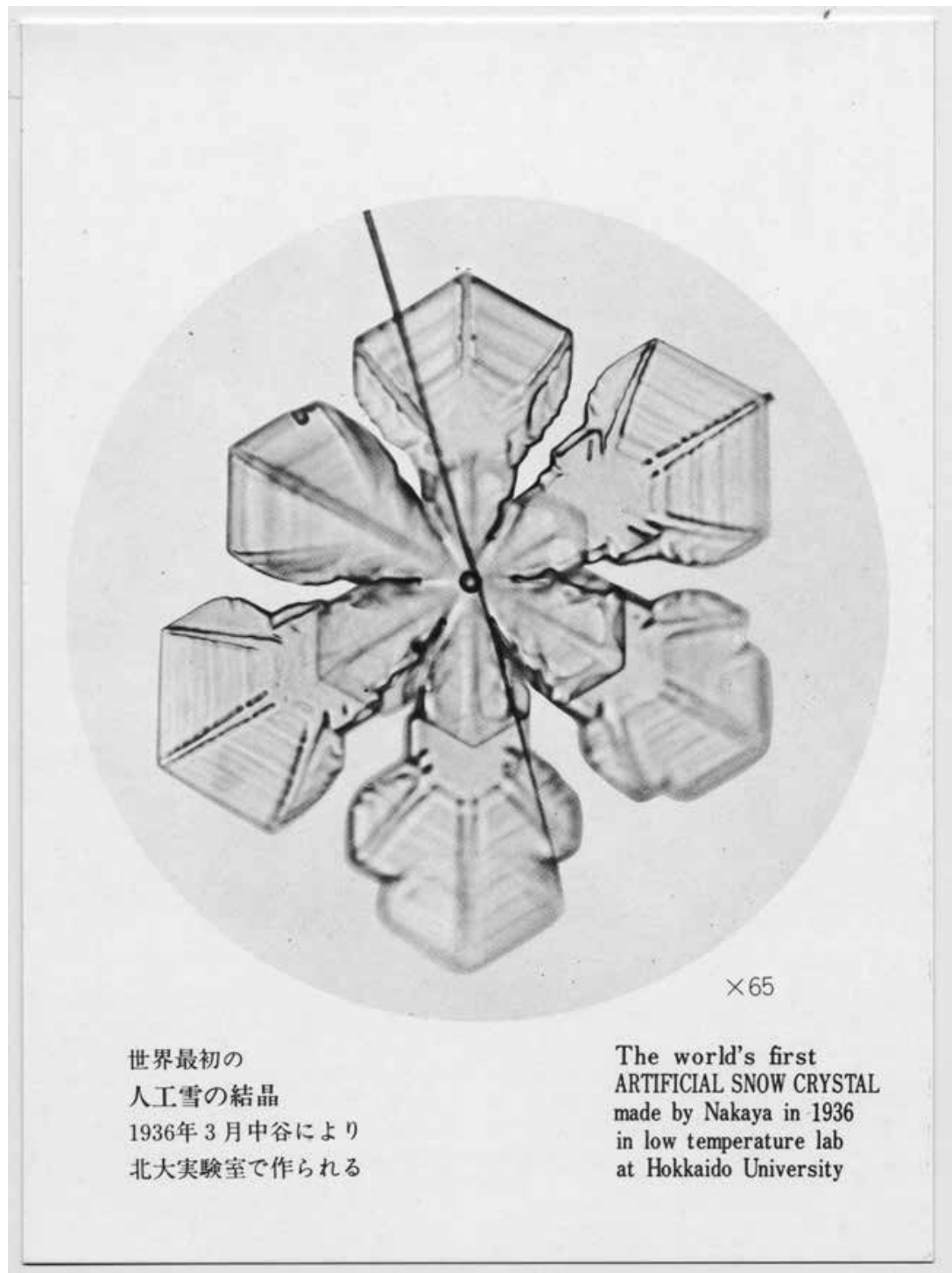

7.1: The World's First Artificial Snow Crystal made by Nakaya Ukichirō at the lowtemperature lab, Hokkaido, Japan, 1936. ๑ Nakaya Ukichiro Foundation.

\section{Engineering the atmosphere}

According to Sloterdijk, the invention of poison gas in the early twentieth century weaponized the very act of breathing air - a hitherto latent 
possibility ${ }^{19}$ The atmosphere thus became a medium for distant killing through the spread of poison gas, and along with this change came the use of smoke screens, fog machines, and fog dispersal techniques in the service of aviation.

As James Fleming notes, 'The dawn of aviation brought new deeds and challenges, with fog dispersal taking centre stage'. ${ }^{20}$ Natural fog, in other words, became an explicit object of systematic technological manipulation through its deployment in aerial warfare. The rise of fog along with clouds, snow, and rain as objects of military research is intimately tied to this strategic understanding of the atmosphere as a prime battlefield in the twentieth century. Pilots especially needed a clear view of the runway, requiring fog dispersal; battleships also benefited from the fog-dispersal technology. Henry G. Houghton, a physical meteorologist from the Massachusetts Institute of Technology, invented an experimental fog clearing machine in the mid-1930s. Houghton created 'artificial fogs in his laboratory and tested means of dispersing them' using pressure nozzles. And his research had direct implications for the technical component of the fog sculpture. ${ }^{21}$

The first successful case of large-scale fog dissipation was the British Royal Air Force's Fog Investigation and Dispersal Operation (FIDO) system deployed in 1944. The chemical engineers working on this project came up with a device to heat up the airfield so that Allied pilots could safely take off and land during foggy conditions. ${ }^{22}$ On the other side of the globe, a team of Japanese scientists led by Nakaya Ukichirō embarked in June 1944 on a similar project to observe and disperse summer sea fog. Having worked on several wartime research projects related to frost heaving, aircraft icing, and lightning at the Institute of Low Temperature Science in the 1930s and early 1940s, Nakaya was a scientist whom the Japanese military entrusted with the strategic task of developing a fog dispersal system.

With the assistance of researchers at the central meteorological observatory, military engineers, and his students from Hokkaido University, Nakaya directed a project studying summer sea fog. In order to collect comprehensive data on density, humidity, scale, and fog droplet size, they rode balloons provided by the Japanese Army and photographed fog droplets day after day. These photographic records provided the visual means of gauging the size

21 Popular Science, p. 39. Houghton's research on pressure nozzles is also mentioned by Nakaya Fujiko. See Nakaya, 1972, p. 220.

22 Fleming, p. 6. 
and density of droplets in the atmosphere. The researchers also deployed time-lapse cinematography to document the appearance and disappearance of sea fog from the top of a nearby coastal mountain. ${ }^{23}$ Along with the prevention of icing on aircraft propellers and frost heaving on the railroad, the clearing of the visual field for aviators became particularly urgent as Japan consolidated its territorial control over northern climate regions such as Manchuria and the Kuril Islands. The scientific study of fog was implicated in the expansion of the Japanese empire-and its eventual demise.

From 1944 to 1945, Nakaya's team tirelessly gathered atmospheric data using balloons, cameras, desiccators, and daily weather maps. They finally devised a 'fog dispersal truck' using makeshift materials one month before Japan's surrender in August $1945 .{ }^{24}$ The end of the war did not bring an end to Nakaya's atmospheric science research, however. And his collaboration with experts from other fields continued. After the war was over, Nakaya worked on the agricultural impact of snow, ice, and frost in the hope of improving the productivity of his war-torn nation after the loss of its oversea colonies. Later he also worked on resource development projects. ${ }^{25}$ In order to continue his research on artificial snow and artificial rain, he sought financial assistance from governmental agencies, including the Allied occupation forces and the U.S. Air Force. Not surprisingly, his involvement in both Japanese and American military research was quite controversial to some. ${ }^{26}$ Others were more forgiving, since Nakaya regarded his involvement in military research as a necessary evil and upheld his ideal of engaging in 'useful' basic research that served the common good. ${ }^{27}$

Between 1952 and 1954, Nakaya joined and worked for the U.S. Army Corp's Snow, Ice, and Permafrost Research Establishment (SIPRE), an organization that he helped establish by serving as an international consultant. It is this type of participation that places Nakaya in the transnational orbit of the military-industrial-academic complex that bridged wartime Japan and Cold War America. To put it differently, by following Nakaya's career we can trace Japan's geopolitical reorientation from World War II to the Cold War period.

One of the American meteorologists Nakaya knew was Vincent Schaefer at the General Electric Research Laboratory. During the Occupation, Schaefer had personally helped Nakaya by procuring American film stock to reshoot his film 
Snow Crystals (1939), which documented his experiments with artificial snow. ${ }^{28}$ Schaefer procured the necessary funds from the classified cloud-seeding project called Project Cirrus (1947-1952), for which he served as a coordinator. ${ }^{29}$

During World War II, Schaefer-like Nakaya - worked on military research related to de-icing techniques. Together with Irving Langmuir, a Nobel Prize-winning chemist who also worked for the GE Research Laboratory, Schaefer developed a method of cloud seeding to artificially induce precipitation. They were the literal 'rainmakers' who contributed to the dual-use technology of weather modification during the Cold War. ${ }^{30}$

Researchers involved in Project Cirrus 'conducted about 250 experiments involving modification of cold cirrus and stratus clouds, warm and cold cumulous clouds, periodic seeding, forest fire suppression, and a notable attempt to modify a hurricane' $3^{3}$ The promise of freely engineering meteorological phenomena seemed like a near-future reality. (Figure 7.2) A 1954 Collier's Magazine article, tantalizingly titled 'Weather Made to Order', describes such futuristic scenarios as 'milking rain or snow from reluctant clouds at the proper time and place..$^{32}$ The practice of weather control, in short, is described as a domestication of nature. The gendered analogy of milking rain or snow also betrays a masculine fantasy of extraction, extended to the atmosphere.

The author of the article, Howard T. Orville, chairman of the Advisory Committee on Weather Control under the Eisenhower administration, further speculated on the future:

How will you have your weather-wetter, drier, warmer in winter, cooler in summer? Or would it appeal to you to have every weekend a fair one, and rain only on Wednesdays? (Even that's conceivable, by stimulating an apparent natural weather 'cycle' of about a week.) Whatever your choice, the time may not be far away when the weather-makers can deliver it. ${ }^{33}$

Orville, a retired Navy officer, also discussed the possible military uses of weather modification, such as intercepting clouds in order to dry up crops and thus to 'strike at an enemy's food supply'.34

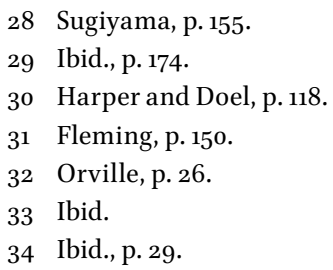




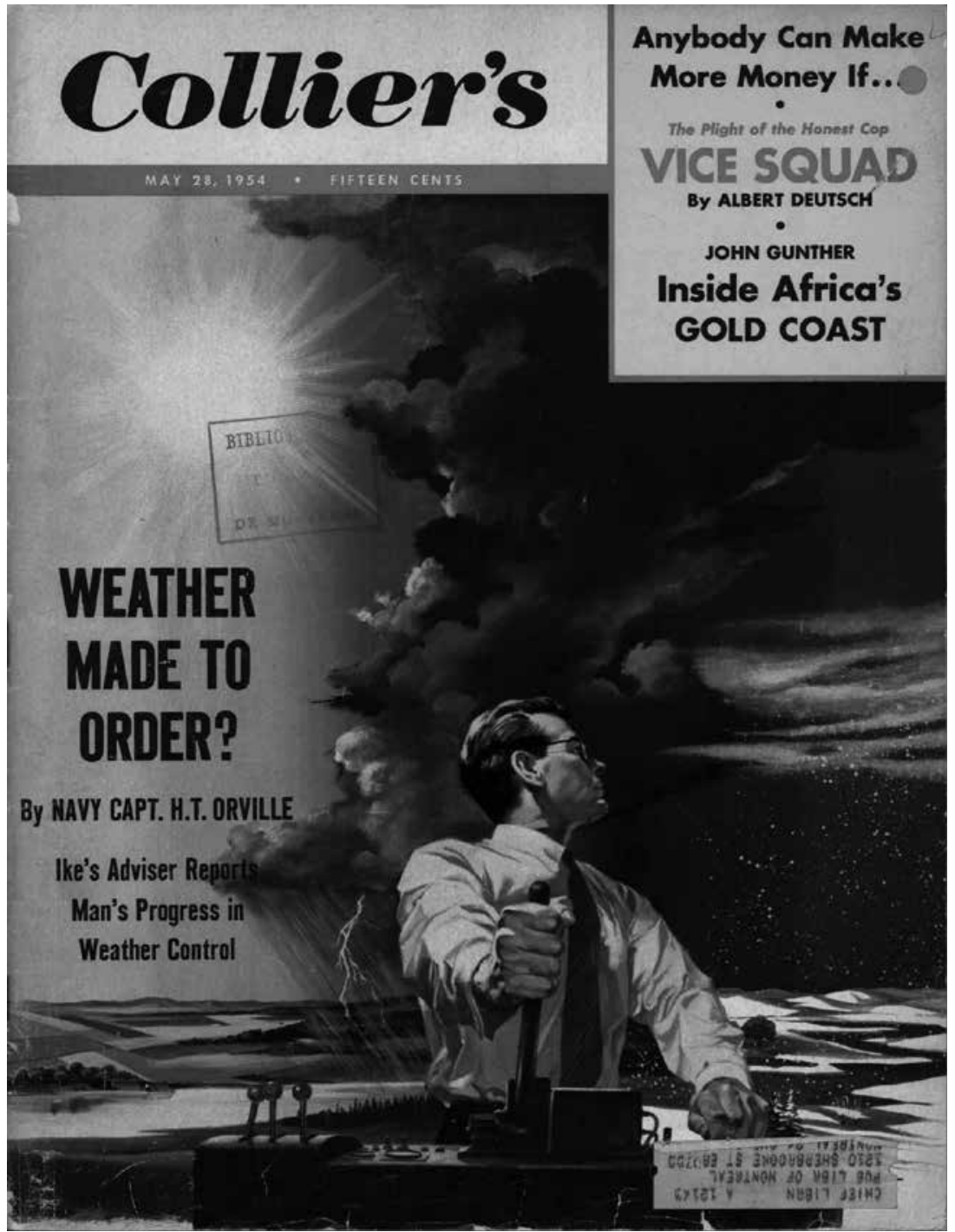

7.2: "Weather made to order? Man's Progress in Weather Control." Collier's Magazine, May 28, 1954.

By the mid-196os, such speculation became a harrowing reality. The political destabilization of Southeast Asia during the Vietnam War and the military potential of 'weather warfare' seemingly convinced the Pentagon to launch weather control as part of its experimental warfare. In preparation, the U.S. government under President Lyndon Johnson tested its secret weather modification techniques for the purportedly humanitarian project 
of alleviating droughts in India. Once it proved effective, large-scale cloudseeding techniques were employed to steer hurricanes above Laos and Vietnam with the intention of prolonging the monsoon season and thus disrupting 'North Vietnam's supply lines that snaked through the Laotian panhandle and into South Vietnam'.35 In short, the military use of weather control up in the air became a potential means of disrupting enemy logistics on the ground.

Such tactical use of weather control further integrated meteorological phenomena into warfare. In so doing, it propelled the ongoing process of atmospheric-explication that began with the invention of poison gas and continued with fog dispersal and its counterpart, smoke screen technology. ${ }^{36}$ While the commercial use of cloud-seeding promised a rosy future for weather on demand - turning arid deserts into fertile croplands by modulating rainfall, preventing flooding, and feeding hydroelectric power plants - the development of weather control is inseparable from its military applications. Of course, this does not mean that the military use of weather control overshadowed its civilian counterpart. In 1950s and 196os Japan, for instance, research projects on experimental weather control, especially on artificial precipitation, were carried out mainly by meteorologists affiliated with hydroelectric power companies supported by the state, which hoped to multiply the production of electricity needed for the nation's rapid economic recovery and further industrial growth. ${ }^{37}$

Regardless of its applications, however, there is one common element to these diverse forms of weather control: their inseparability from the question of security. From its military application to warfare to its civilian application to ensure food and water security, controlling weather became tied to the geopolitics and biopolitics of the twentieth century. That is to say, the military application of weather control became inseparable from the geopolitical influences of nation-states over their given or disputed territories, as well as the biopolitical management of populations and their access to crops or water. Weather control in this sense was a dual-use technology;

36 Citing the 1996 study by the U.S. Air Force titled 'Weather as a Force Multiplier: Owning the Weather in 2025', Sloterdijk lists possible means of weather control: 'Based on current projections, the range of weather weapons will include: the maintaining or hindering of vision in air space; the increasing or decreasing the troops' comfort levels (i.e. their morale); thunderstorm enhancement and modification; rainfall prevention over enemy territories and the inducing of artificial drought; the intercepting and blocking of enemy communication; and preventing the enemy from performing analogous weather activities.' Sloterdijk, p. 64.

37 See, for instance, Yoshimoto, pp. 12-21. 
at the most basic level, it was an instrument for managing the environment in both peacetime and wartime, an instrument that both sustained the biological life and ensured the survival of the modern nation-state.

In this regard, it is worth remembering Sloterdijk's point that explicating the atmosphere reveals the existential insecurity of living in a technologically mediated environment. With the militarization of poison gas and weather control, technological modernity intensified the sense of insecurity associated with the environment, as the air we breathe potentially contains poison, and the clouds above us are possible meteorological weapons. In the compensatory manner, this intensified sense of atmospheric insecurity further propels technological inventions to create countermeasures, such as the inventions of the gas mask, air-purification, and so on. The eventual establishment of the regulatory Weather Control Commission in the United States (directly modelled after the Atomic Energy Commission) fits this framework. ${ }^{38}$ The weaponization of weather control could-like nuclear weapons-become lethal if it got out of control. Even uncontrolled air pollution can be lethal, as indicated by deaths caused by heavy smog. Such incidents of industrial air pollution are considered 'inadvertent weather modification'.39

The sense of insecurity posed by weather modification is, however, not an exception but a rule of technological modernity. It is a salient example of the paradoxical process of atmospheric-explication in general. According to Sloterdijk, 'modernity conceived as the explication of the background givens thereby remains trapped in a phobic circle, striving to overcome anxiety through technology, which itself generates more anxiety'. ${ }^{40}$ That is to say, the explication of the atmosphere creates a vicious cycle: the more we learn about the vulnerability of the atmosphere, the more we turn to technology to compensate for and control this vulnerability. ${ }^{41}$ The military investment in the weaponization of the weather, in this regard, is part of the ongoing process of atmospheric-explication that also reveals the human desire to dwell inside a 'climate-controlled' environment. ${ }^{42}$ The revelatory capacity of technology to explicate the atmosphere is inseparable from the artifice of human dwelling

38 Harper and Doel, p. 119.

39 Tsuchiya, p. 213.

40 Sloterdijk, p. 79 .

41 Ibid.

42 As Eduardo Mendieta puts it, all technology for Sloterdijk is primordially 'space-originating technology'. Mendieta, 73. In his essay 'The Age of the World Picture,' Heidegger criticized this way of conceiving technology as an instrument as a hallmark of modernity when the objectification of the world vis-à-vis the relational centre of the subject becomes the basis of knowledge production. 
as a constant effort to engineer the environment. Needless to say, the effort to secure and expand habitable environments through engineering the land, ocean, and sky is a continuous thread that runs through the history of industrialization and colonialism and that characterizes modernity.

\section{Fog sculpture}

It is against this broad context of the ongoing process of atmosphericexplication that I want to situate the invention of artificial fog as an artistic medium by Nakaya Ukichirō's daughter, Nakaya Fujiko. Her innovative use of water-based artificial fog, which generated a microclimate around the Pepsi Pavilion, cannot be separated from the concurrent epistemological and technological process of atmospheric-explication. It is not coincidental that the artistic use of fog became both conceptually salient and technologically feasible at the precise moment when the adverse effects of weather modification (including the inadvertent kind, in the form of air pollution) were slowly becoming clear.

To put it schematically, then, the microclimate control at the Pepsi Pavilion is a scaled-down version of commercial, military, and industrial geoengineering that controlled and modified weather. This is not to disregard the aesthetic intention of the artist who is known for her commitment to environmental activism and her critique of mercury pollution. Rather, I am highlighting the ambivalent duality of the technologically mediated process of atmospheric-explication that binds otherwise heterogeneous experiments undertaken by artists, scientists, and engineers.

Although the ultimate inventor of the pressurized nozzle-based fogmaking machine for the Pepsi Pavilion was American cloud physicist Thomas Mee, Nakaya Fujiko settled on this apparatus after a long process of experimentation. To better understand how the fog sculpture sits at the point of convergence between these two lines of descent (of visualizing and engineering the atmosphere), let us look closely at the technological and scientific assistance that Nakaya received to make this artwork. The idea to shroud the exterior of the geodesic dome with artificial fog emerged at the early planning stage of the Pepsi Pavilion by E.A.T., a group to which she belonged since her participation in the 9 Evenings event in 1966. ${ }^{43}$ (She

43 Strictly speaking, E.A.T. as a group was formally established after the success of 9 Evenings. For more on the history of E.A.T., see the 2003 exhibition catalog E.A.T. - The Story of Experiments in Art and Technology. 


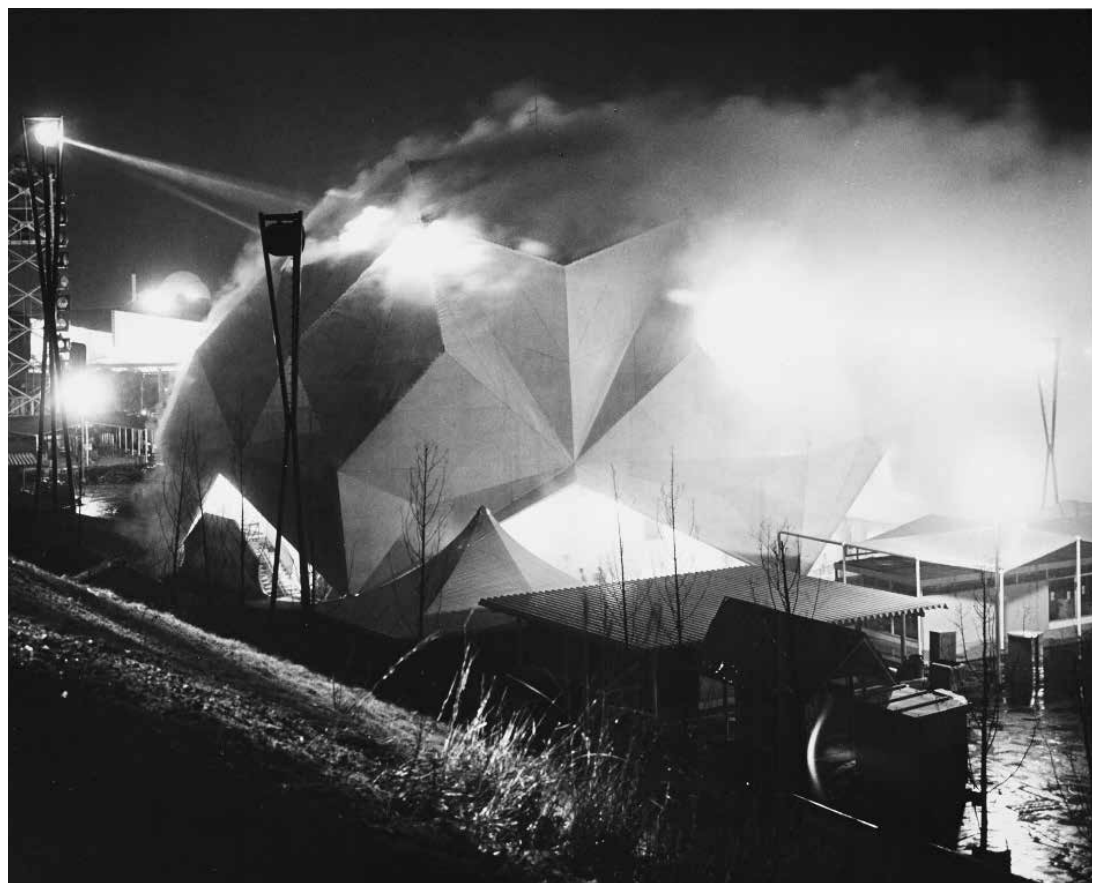

7.3: Experiments in Art \& Technology, The Pepsi Pavilion at Osaka Expo '70, (photo: Shunk-Kender). $\odot$ Roy Lichtenstein Foundation, courtesy Experiments in Art \& Technology.

also served as the coordinator for E.A.T.'s Tokyo headquarters.) Throughout the second half of the 196os, Nakaya and other Japanese artists including Ichiyanagi Toshi, Takahashi Yūji, Takemitsu Tōru, Isobe Yukihisa, Usami Kenji, Morioka Yūji, and Kobayashi Hakudō participated in E.A.T. projects that included 9 Evenings (1966), Some More Beginnings (1968), the Pepsi Pavilion at Expo '70 (1970), and Utopia: Q\&A 1981 (1971). ${ }^{44}$ Among these, the commissioned project of designing the Pepsi Pavilion was by far the largest project that E.A.T. undertook. The project involved 75 artists, scientists, and engineers, nurturing interdisciplinary collaborations among them.

Enveloping the dome with artificial fog was central to the group's overall objective of turning the pavilion into a 'living responsive environment'. ${ }^{45}$ They wanted this artificial environment to register and respond to ambient factors such as wind, temperature, humidity, and the movement of visitors in 
real time. ${ }^{46}$ (Figure 7.3) However, the technical feasibility posed a challenge. According to Nilo Lindgren, a journalist who followed its planning stage, 'No one knew whether or not it was actually possible to make a fog, but the idea persisted and survived'. ${ }^{47}$ Nakaya, who had an avid interest in the ephemeral form of clouds, became a key person in charge of executing this ambitious idea.

There are many different ways of artificially creating fog. As Nakaya notes in her essay 'The Making of "Fog" or Low-Hanging Stratus Clouds', one can use water (as she ultimately did for the Pepsi Pavilion), chemicals, oil, or smoke. She opted for using pure water in order to accommodate the aesthetic requirements of the project. Water, rather than other substances, was more suitable for the following reasons:

My choice was based on what I felt were the three most important requirements of the fog for our purpose:

1. Visibility: it should scatter enough light to reduce considerably the visibility of the objects behind, and, at the same time, make visible the otherwise invisible dynamics of atmosphere;

2. Tangibility: it should feel soft and cool to the skin;

3. Vulnerability: it should be subject to atmospheric conditions; it should disappear, not persist. ${ }^{48}$

Among these three conditions, the first (visibility) and the third (vulnerability) are particularly interesting in light of the scientific investment in fog discussed earlier and the weaponization of fog. Fog-or low-hanging stratus clouds, as Nakaya calls them-is marked by its versatility. When used to conceal objects behind it, it works like a smokescreen. But it can also refract and diffuse light. Some of her later projects thus make clever use of laser beams, as in the case of her collaborative work with Bill Viola (Fog Sculpture, 1980), which took advantage of fog's optical effects of refraction and diffusion and served as an ambient screen. ${ }^{49}$

Moreover, fog's constant metamorphosis can draw viewers' attention to ambient environmental factors such as wind, temperature, humidity, and even the movement of visitors (which makes it an ideal 'interactive' or 'responsive' medium for environmental art). Put another way, a fog

46 Nakaya Fujiko writes: 'Constantly changing atmosphere acted as a mold; the Fog sculpture was given its form instantaneously by the physical condition of its environment.' Nakaya, 1972, p. 207.

47 Lindgren, p. 23.

48 Nakaya, 1972, p. 209.

49 Viola, p. 150. 
sculpture engages in the process of atmosphere-explication; it renders explicit latent conditions of the atmosphere that otherwise remain imperceptible as an environmental given..$^{50}$ Generated by atomizing nozzles attached to the roof of the geodesic dome, this site-specific fog sculpture cascaded, drifted, and gathered outside the dome, responding to the ever-changing patterns and density of air currents, temperature, humidity, and light. (Figure 7.4)

What is unique about the technical support of this work is its use of water-based, rather than chemical, fog. In using water, the work simulated natural fog and provided the pavilion with its own microclimate. Yet this microclimate was completely artificial. Nakaya notes: 'The only request I made to my partner-scientist was that I wanted dense, bubbling-out fog, as close a simulation as possible to natural fog in its physical nature, to cover the entire Pavilion, with perhaps drop-size control added to make rain once in a while. ${ }^{1}$

At the preparatory stage for designing the fog-making system, Nakaya spent six months gathering statistical data on the local weather patterns in Senri, where the world's fair was to take place. She carefully studied the layout of the fairground and the topography of the surrounding area to understand its potential physical impact on the aesthetic process of fog-making. She also consulted a number of Japanese physicists and meteorologists in order to explore the technical feasibility of producing pure water fog..$^{2}$ Two of the scientists she sought advice from were Magono Chōji and Higashi Akira at Hokkaidō University. They were both students of her father, Nakaya Ukichirō, and had participated in his wartime research project on fog dispersal in the first half of the 1940s. Nakaya Fujiko's path thus directly crossed with that of her father in her quest for the scientific and technical support she needed to create this exquisite environmental artwork. By generating simulated fog and rain, this site-specific work also participated in the experimental practice of weather control, which developed in the 1950 and 1960 . As I discussed in previous sections of this chapter, the attempt to visualize otherwise invisible atmospheric phenomena has generated scientific and artistic experiments since the nineteenth century. The attempt to control weather and to engineer man-made fog, rain, and

50 Sloterdijk, p. 47 .

$5^{1}$ Nakaya, 1972, p. 220.

52 Nakaya Fujiko writes: 'The area around the Pavilion was open except for the southwest side where it was backed up by a small hill; there were no other obstacles nearby, such as tall buildings or trees, to serve as windbreaks.' Nakaya, 1972, p. 208. 


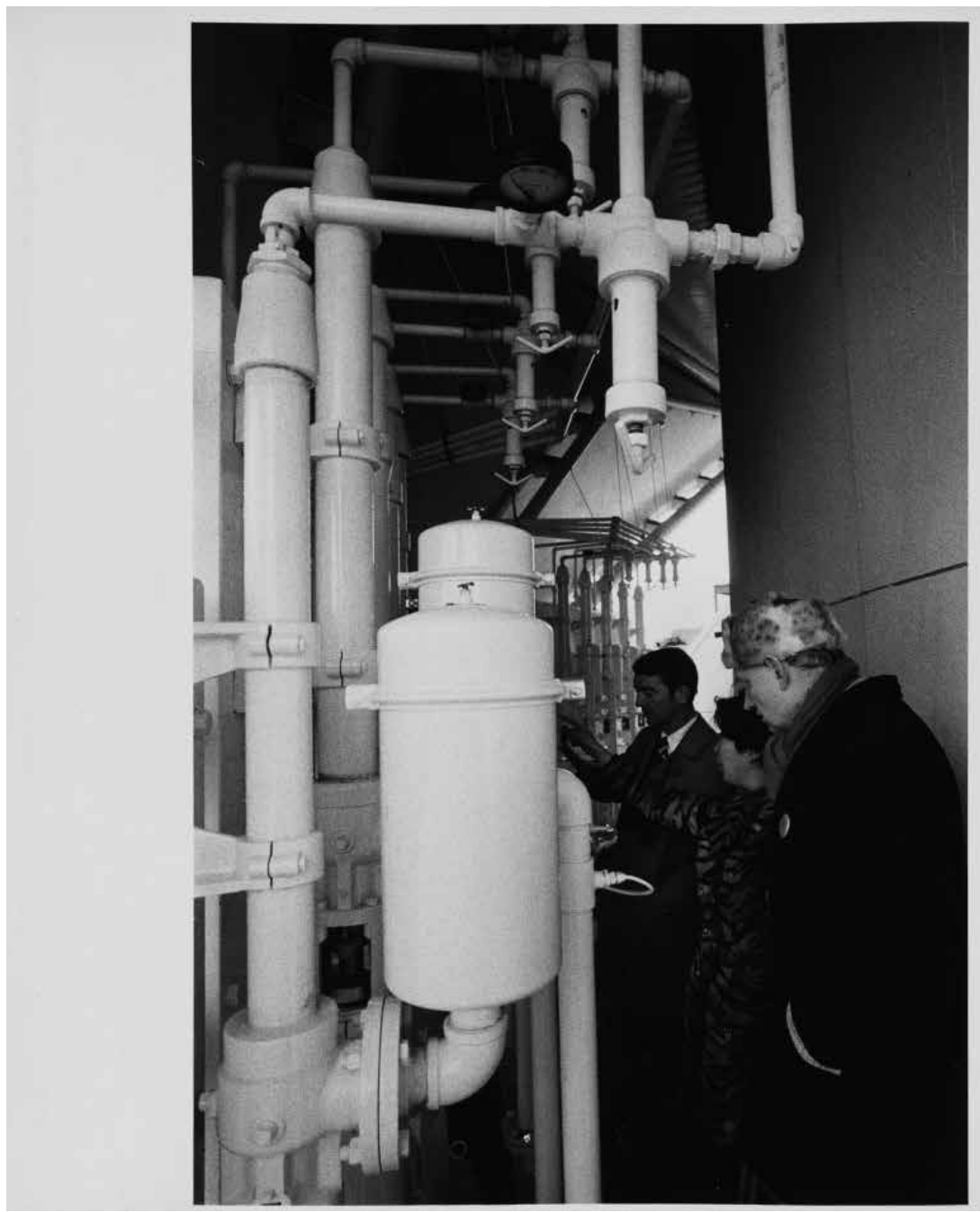

7.4: Billy Klüver, Fujiko Nakaya and Thomas Lee inspecting the pumps for the cloud sculpture at Pepsi Pavilion, Osaka, '70. ๑ Roy Lichtenstein Foundation, courtesy Experiments in Art \& Technology.

snow belongs to a different lineage, even though both traditions share a desire to explicate the atmosphere. The genealogical nexus between the two Nakayas point to the intersection of these two lineages. 


\section{Site-specific weather}

Pushing the line of genealogical thinking that binds fog sculpture to weather control further, we may arrive at a new way of conceptualizing screens and the history of media as well as a new conception of site-specificity as a geopolitically located practice. To begin, we may think of the practice of engineering the atmosphere as both site-specific and scalable. One can move from modulating an atmosphere at the miniature scale of a cloud chamber to the median scale of a pavilion and to a much larger scale of an entire region. Moreover, as one moves from the enclosed space of the laboratory to the larger space of open experiments, the geopolitical configuration of the technology changes as well. Various geographical, climatological, meteorological, socio-political, and technical factors are at play when weather modification is performed. At this point, geopolitics (literally, the politics of the earth) provides a necessary perspective for thinking about the specificity of a given site of weather modification. It is in this sense-of the specificity of the given environment within which the work of weather control takes place - that we may use the term site-specificity.

Although this term comes out of the discipline of art history and holds a privileged relationship to the field of sculpture, I am more interested in its literal connotation, of the givenness of the site. ${ }^{53}$ What happens if we move away from the formal or conceptual constraints of a site-specific art work (though Nakaya Fujiko's fog sculpture surely can be analyzed from that angle) and towards the geopolitical specificity of the notion of site itself? Here, I am using the term to deliberately expand this notion to include a site's environmental constraints, wherein the broadly conceived act of engineering the atmosphere may take place. To do so is to decouple an artwork from its disciplinary context and place it in a different framework of analysis. To read the singular work of fog sculpture and the systematic operations of weather control side by side is to pay attention to their common ground. This ground, I argue, is the epistemological and technological conditions of mimetic experimentation, the attempt to artificially replicate meteorological phenomena.

Expanding the conceptual affordance of the term site-specificity outside the history of art in this manner also allows us to attend to multiple senses

53 I am thinking in particular of debates around Rosalind Krauss's seminal 1979 essay, 'Sculpture in the Expanded Field'. For its enduring relevance to the fields of sculpture, architecture, and conceptual art, see Papapetros and Rose, 2014. 
of the term medium. In the context of art history, the term refers to an artistic medium - the material and technical supports and formal conventions of an artwork - while the same term in the context of media studies predominantly signifies technical channels and intermediary agents of communication, transmission, and storage. The recent recuperation of medium in the spatial and environmental sense of milieu-literally the middle-by media scholars offers a heuristic means of rearticulating the material support of environmental artworks, such as Nakaya's fog sculpture, in terms of this etymological affinity between milieu and medium. The idea of elemental media - water, air, and sky as communication media-proposed by Peters, for instance, pushes this line of thinking to incorporate natural physical phenomena, including the weather, back into the history of technical media. "Media," understood as the means by which meaning is communicated, sit atop layers of even more fundamental media that have meaning but do not speak', writes Peters. For him, 'the old idea that media are environments' must be flipped if we were to understand media in this expanded sense, since 'media are ensembles of natural element and human craft'. ${ }^{54}$ To understand the significance of the fog sculpture from this emergent perspective of environmental media means that we expand the use of the term medium in relation to this artwork. As I have argued throughout this chapter, this expanded sense of the medium allows us to incorporate the development of its technical apparatus through the history of science and technology into its genealogical framework.

\section{Conclusion}

In conclusion, I want to briefly discuss an afterlife of the fog-making machine used for Nakaya's fog sculpture at the Pepsi Pavilion. Originally invented by Mee and his engineers for weather control, the apparatus had practical applicability beyond the realm of art. As Billy Klüver proudly notes, it 'offered interesting possibilities for environmental irrigation systems, outdoor air conditioning, and protection of crops from frost'. ${ }^{5}$ The original application of the fog machine was aesthetic, but its afterlife was not. This fog-making technology (or more precisely, the evaporative cooling process derived from it, which Mee Industries Inc. developed after Expo '70) is used today to cool 
down data centres. ${ }^{6}$ The metaphorical clouds of networked data storage and processing systems are thus directly linked to the physical clouds of fog sculpture by the historical path of a shared apparatus.

Seen from the standpoint of media studies, then, the invention of the fog medium belongs to the wider history of atmospheric media. Noting the ubiquitous presence of networked computational devices and micro-sensors in our environments and their capacity to filter data and condition our sensory experiences of the world at the imperceptible level, Mark Hansen has proposed the term 'atmospheric media'. Marked by anticipatory temporality, these atmosphere media, he argues, have reconfigured the relationship between humans and their environments. ${ }^{57}$

Recently, Nakaya Fujiko and a collaborator placed meteorological sensors at various places around an installation site in order to record ambient data such as temperature, humidity, and wind speed and direction. These data were then run through a special computer program that controlled the nozzles of a fog-making machine so that the shape of the fog directly responded to, and interacted with, the surrounding environment. ${ }^{8}$ Here, current debates about atmospheric media come into sharp focus through the technological articulation of artificial fog and computational media.

Commenting on the contemporary resurgence of meteorological metaphors in discussions of computational media, Peters writes: 'Fantasies of what Mark Hansen calls "atmospheric media" presupposes an electrical grid. Information is not smokeless. Google's servers burn up millions of dollars of electricity every month and produce an enormous amount of heat that requires cooling. ${ }^{.59}$ Mee's fog-making apparatus and other air-conditioning systems installed at data centres worldwide are precisely the infrastructure that sustains the electrically powered servers of today's Internet-related service providers. The fog-making machine, in short, is the infrastructure of contemporary atmospheric media that Hansen discusses. In this regard, it is worth mentioning that the MeeFog system is installed at none other than Facebook's data centre in Prineville, Oregon. ${ }^{60}$ The low-hanging cloud or fog that enveloped the Pepsi Pavilion at Expo '70 thus resurfaces not only in Nakaya's later and similarly spectacular artworks (such as the fog

56 'Data Center Uses MeeFog System', Mee Industries Incorporated Homepage. http://www.meefog. com/case-studies-post/data-center/data-center-uses-meefog-system-keep-operating-heat-wave/.

57 Hansen, p. 5 .

$5^{8}$ See Ozaki, 2017.

59 Peters, p. 332.

60 'Facebook Uses MeeFog System', Mee Industries Incorporated Homepage. http://www. meefog.com/case-studies-post/data-center/facebook/. 
sculpture for the Blur Building designed by architects Elizabeth Diller and Ricardo Scofidio for the 2002 Swiss Expo) but also in the much less visible walls and pipes of data centres where digital clouds are stored, accessed, modulated, and cooled. The distance between these two manifestations of artificial fog may seem far and wide, yet, as I have argued in this chapter, they belong to the same genealogy.

Pointing out the frequent recycling of Cold War bunkers into data centres, which inherit what he calls a 'bunker mentality', Tung-Hui Hu argues that data centres sit at 'the border between the dematerialized space of data and the resolutely physical buildings they occupy'. ${ }^{61}$ A similar tension exists between the air-conditioning systems that support the operation of data centres and the engineering of the atmosphere by artists, scientists, and engineers that I traced as the genealogy of the fog medium. Arguably, the bunker mentality oriented towards ensuring security is itself an effect of the existential insecurity generated by the process of atmospheric-explication. The repurposing of the fog-making system invented for the Pepsi Pavilion to cool down data centres partakes in this ongoing process of atmosphericexplication. Going back to Hu's discussion of the bunker mentality for a moment, we may surmise that insecurity about the loss of data stored in the digital cloud is part of what Sloterdijk has called the phobic circle of explication. As we explicate the atmosphere through technology, it amplifies our anxiety about its vulnerability, which in turn prompts more technological solutions to manage and control this vulnerability.

The epistemological implications of atmospheric-explication, however, are not limited to the management of anxiety and insecurity generated by technology. What I have called the lineage of visualizing the atmosphere is a mode of explication that also gave rise to a series of aesthetic experiments that took the ephemeral matter of cloud-like substances (e.g. smoke, mist, fog, and helium-filled balloons) as projection and installation media. The duality of fog as a screening device to conceal and to reveal, to undermine and to increase visibility of the environment has thus served different functions in the realm of contemporary art. One may well read these artworks as symptoms of the existential insecurity generated by the technological explication of the atmosphere. We may also situate them as integral components of the genealogy of atmospheric computational media and the infrastructure that sustains it. To do so enables us to directly link the existential insecurity of atmospheric-explication discussed by Sloterdijk to the material infrastructure of data centres. The increasing embeddedness of 
computational media in our physical environment and the ever-intensifying traffic of electronic signals in our everyday lives seem to demand that we shift our perspective from the old model of technical media towards atmospheric phenomena as media. To do so without collapsing metaphors and histories is a challenge to which this chapter has attempted to respond.

When we attend to the genealogical dimension of these media rather than the phenomenological experiences they engender in the present, we inevitably come up against another challenge: the geographically, politically, and institutionally specific contexts within which certain technological apparatus were developed, tinkered with, and put to experimental use. The historicity of the fog-making machine used for the fog sculpture at the Pepsi Pavilion in 1970 is a salient reminder of such specificity. And this specificity, as in many other instances of media, is deeply entangled with the geopolitical configuration and reconfiguration of the world. In other words, the work occupies multiple positions depending on the analytical framework: it is at once an exemplary atmospheric screen; an exquisite environmental artwork; an emblem of the art-and-technology movement that facilitated collaborations among artists, scientists, and engineers; and a scaled-down version of military and civilian applications of weather control and geoengineering. There's no doubt that we can find more instances of such varied articulations among the works of other contemporary media artists. But to overemphasize their technological novelty would risk obscuring their historical conditions of possibility. To look through the dust of archives that led to such articulations of artificial and technical media is a way to see fog in its longer history as a medium of scientific inquiry and artistic experiment.

\section{Works Cited}

Bao, Weihong. Fiery Cinema: The Emergence of An Affective Medium in China, 1915-1945. Minneapolis: University of Minnesota Press, 2015.

Braun, Marta. Picturing Time: The Work of Etienne-Jules Marey (1830-1904). Chicago: University of Chicago Press, 1992.

Casetti, Francesco. The Lumière Galaxy: Seven Key Words for the Cinema to Come. New York: Columbia University Press, 2015.

Doane, Mary Ann. The Emergence of Cinematic Time: Modernity, Contingency, the Archive. Cambridge, MA: Harvard University Press, 2002.

Duguet, Anne-Marie. 'Naturally Artificial.' In Fujiko Nakaya:Fog, Kiri, Brouillard, 30-39. Paris: Editions Anarchive, 2012. 
Fleming, James Rodger. Fixing the Sky: The Checkered History of Weather and Climate Control. New York: Columbia University Press, 2010.

Galison, Peter. Image and Logic: A Material Culture of Microphysics. Chicago: University of Chicago Press, 1997.

Gulliver, Shuzo Azuchi. 'Flying Focus.' In Ekusupandeddo shinema saikō /Japanese Expanded Cinema Reconsidered, exhibition catalogue, 71. Tokyo: Tokyo Shashin Bijutsukan, 2017.

Hansen, Mark B.N. Feed-Forward: On the Future of Twenty-First Century Media. Chicago: University of Chicago Press, 2015.

Harper, Kristine C. and Ronald E. Doel. 'Environmental Diplomacy in the Cold War: Weather Control, the United States, and India, 1966-1967.' In Environmental Histories of the Cold War, edited by J.R. McNeill and Corinna R. Unger, 115-138. Cambridge: Cambridge University Press, 2010.

Higashi, Akira. Yuki to kōrino kagakusha Nakaya Ukichirō. Tokyo: Hokkaido Daigaku Tosho Kankōkai, 1997.

Hinterwaldner, Inge. 'Parallel Lines as Tools for Making Turbulence Visible.' Representations 124.1 (Fall 2013): 1-42.

Hu, Tung-Hui. A Prehistory of the Cloud. Cambridge, MA: The MIT Press, 2015. Huhtamo, Erkki. 'The Sky Is (Not) the Limit: Envisioning the Ultimate Public Media Display.' Journal of Visual Culture 8.3 (2009): 329-348.

Klüver, Billy. Atarashii taiken no ba: Pepshi kan no 'ikita kankyō.' Translated by Nakaya Fujiko. Bijutsu techō (July 1970): 94-108.

Klüver, Billy. 'The Pavilion.' In Pavilion: Experiments in Art and Technology, edited by Billy Klüver, Julie Martin, and Barbara Rose, ix-xvi. New York, E.P. Dutton \& Co., Inc, 1972 .

- — and Julie Martin, eds. E.A.T. - The Story of Experiments in Art and Technology, exhibition catalogue. Tokyo: NTT InterCommunication Center, 2003.

_- Julie Martin, and Barbara Rose, eds. Pavilion: Experiments in Art and Technology. New York: E.P. Dutton \& Co., Inc, 1972.

Kobayashi Hideo. 'Teion Kekyūjo o meguru gunji kenkyū.' Kokumin no kagaku (March 1955): 19-25.

Krauss, Rosalind. 'Sculpture in the Expanded Field.' October 8 (Spring 1979): 30-44. Lindgren, Nilo. 'Into the Collaboration.' In Pavilion: Experiments in Art and Technology, edited by Billy Klüver, Julie Martin, and Barbara Rose, 3-59. New York, E.P. Dutton \& Co., Inc, 1972.

MacDonald, Scott. A Critical Cinema 2: Interviews with Independent Filmmakers. Berkeley and Los Angeles: University of California Press, 1992.

Machimura Takashi. Kaihatsu shugino kōzō to shinsei. Tokyo: Ocha no mizu shobō, 2011. 
Marvin, Carolyn. When Old Technologies Were New: Thinking About Electric Communication in the Late Nineteenth Century. Oxford: Oxford University Press, 1988.

Mee Industries Incorporated. 'Data Center Uses MeeFog System.' MeeFog.com. http://www.meefog.com/case-studies-post/data-center/data-center-uses-meefogsystem-keep-operating-heat-wave/. Accessed 26 May 2017.

——. 'Facebook Uses MeeFog System.' MeeFog.com. http://www.meefog.com/ case-studies-post/data-center/facebook/. Accessed 27 May 2017.

Mendieta, Eduardo. 'A Letter on Überhumanismus.' In Sloterdijk Now, edited by Stuart Elden, 58-76. Cambridge, UK: Polity, 2012.

Nakaya Fujiko. 'Kūki to mizu.' Special Issue on Expo '7o, Bijutsu techō (July 1970): 105-108.

——. 'Making of "Fog" or Low-Hanging Stratus Cloud.' In Pavilion by Experiments in Art and Technology, edited by Billy Klüver, Julie Martin, and Barbara Rose, 207-223. New York, E.P. Dutton \& Co., Inc, 1972.

Nakaya Ukichirō. 'Gunji kenkyū to wa nanika.' Hokudai kikan (January 1955): 27-28.

Orville, Howard T. 'Weather Made to Order?' Collier's Magazine, 28 May 1954.

Okazaki Kenjirō, "The lucid, unclouded fog - the movement of bright and swinging water particles." In Fujiko Nakaya: Fog, Kiri, Brouillard, 6o-74. Paris: Editions Anarchive, 2012.

Ozaki Tetsuya. 'Nakaya Fujiko + dNA: MU.' ART iT. http://www.art-it.asia/u/ admin_exrev/HsLPfgloEvCVGioBUwXu/. Accessed 18 March 2017.

Packer, Randall. 'The Pepsi Pavilion: Laboratory for Social Experimentation.' In Future Cinema: The Cinematic Imaginary After Film, edited by Jeffrey Shaw and Peter Weibel, pp. 144-149. Cambridge, MA: The MIT Press, 2003.

Papapetros, Spyros and Julian Rose, eds. Retracing the Expanded Field: Encounters between Art and Architecture. Cambridge, MA: MIT Press, 2014.

Peters, John Durham. The Marvelous Clouds: Toward a Philosophy of Elemental Media. Chicago: University of Chicago Press, 2015.

Popular Science. 'Fog Wiped Out by Chemical Spray.' October 1934.

Reynolds, Roger. Cross Talk Intermedia I. Newsletter for Institute of Current World Affairs, 10 May 1969. http://www.icwa.org/wp-content/uploads/2015/11/PR-20. pdf. Accessed 18 March 2017.

Ross, Julian. Beyond the Frame: Intermedia and Expanded Cinema in 1960-1970s Japan. PhD diss., The University of Leeds, 2014.

Sas, Miryam. 'By Other Hands: Environment and Apparatus in 196os Intermedia.' In The Oxford Handbook ofJapanese Cinema, edited by Daisuke Miyao, pp. 383-415. Oxford: Oxford University Press, 2014.

Sloterdijk, Peter. Terror From the Air. Translated by Amy Patton and Steve Corcoran. Cambridge, MA: MIT Press, 2009. 
Somaini, Antonio. 'Walter Benjamin's Media Theory: The Medium and the Apparat.' Grey Room 62 (January 2016): 6-41.

Starosielski, Nicole. The Undersea Network. Durham, NC: Duke University Press, 2015. Sugiyama Shigeo. Nakaya Ukichirō: Hito no yaku ni tatsu kenkyū o seyo. Tokyo: Mineruva shobō, 2015 .

Tsuchiya Iwao. 'Kishō seigyo, Kikō kaizō.' Kishō kenkyū nōto 104 (June 1970): 143-264. Viola, Bill. 'Music for Fog Sculpture Event by Fujiko Nakaya, Kawaji Onsen, Japan, 1980.' In Fujiko Nakaya: Fog, Kiri, Brouillard, edited by Fujiko Nakaya and AnneMarie Duguet, 150-155. Paris: Editions Anarchive, 2012.

Williamson, Colin. Hidden in Plain Sight: An Archaeology of Magic and the Cinema. New Brunswick, NJ: Rutgers University Press, 2015.

Yoshimoto, Hideyuki. 'Denki jigyō to jinkō kōu.' Denryoku, 46.5 (May 1962): 12-21.

\section{About the Author}

Yuriko Furuhata is associate professor in the Department of East Asian Studies, an associate member of the Department of Art History and Communication Studies, and a faculty member of the World Cinemas Program at McGill University. She works in the areas of film and media theory, Japanese cinema and media studies, visual culture, and critical theory. She is the author of Cinema of Actuality:Japanese Avant-Garde Filmmaking in the Season of Image Politics and has published articles in journals such as Grey Room, Screen, and New Cinemas. She is currently working on a book, tentatively titled Atmospheric Control: A Transpacific Genealogy of Climatic Media, exploring the historical connections between Japanese environmental art, weather control, and cybernetic architecture. 
